\title{
Implementation of information collecting tools using mobile terminals useful for efficient infrastructure maintenance
}

\author{
Miki Kuroki* \\ Graduate School of Science and Engineering, \\ Ibaraki University, Japan \\ Email: 14nd307r@vc.ibaraki.ac.jp \\ *Corresponding author \\ Michitoshi Niibori \\ Learning-i, Ltd, \\ Hitachi, Ibaraki 316-8511, Japan \\ Email: niibori@gmail.com
}

\section{Tomoyuki Ishida and Tatsuhiro Yonekura}

Department of Computer and Information Sciences,

Ibaraki University, Japan

Email: tomoyuki.ishida.49@vc.ibaraki.ac.jp

Email: tatsuhiro.yonekura.z@vc.ibaraki.ac.jp

\begin{abstract}
While the aging of social infrastructure in Japan is advancing, the number of technical experts responsible for infrastructure management has drastically decreased, which has become the major problem to solve social infrastructure aging problems. In order to build a social infrastructure management system with the collaboration from citizens, a 'citizens' participation with ICT technology' was constructed in this research to make it possible for citizens to report the malfunction of social infrastructure, including the situation, the position and the details to the administration of the government. Then a social experiment utilising this system was conducted in two different municipalities with the participation of citizens. Finally, the effectiveness of the system and the problems for dissemination were verified through a questionnaire survey.
\end{abstract}

Keywords: infrastructure management; maintenance; citizens' participation; ICT; social experiments.

Reference to this paper should be made as follows: Kuroki, M., Niibori, M., Ishida, T. and Yonekura, T. (2018) 'Implementation of information collecting tools using mobile terminals useful for efficient infrastructure maintenance', Int. J. Space-Based and Situated Computing, Vol. 8, No. 1, pp.9-19.

Biographical notes: Miki Kuroki received his BS and MS in Engineering from the College of Science and Technology, Nihon University in 1994 and 1996. Currently, he is taking a doctor's course at the Graduate School of Science and Engineering, Ibaraki University. His research interests include web application system, smartphone application, and infrastructure management system. He is a member of Japan Society of Civil Engineers (JSCE).

Michitoshi Niibori received his BE degree from the Ibaraki University. Just before his graduation, he founded the start-up company Learning-i, Ltd. as its President. His research and business interests are focused on web-based systems and the internet of things.

Tomoyuki Ishida received his BS and MS in Software and Information Science from the Iwate Prefectural University in 2004 and 2006 and PhD degree in the same university in 2010. Currently, he is a Lecturer in the Ibaraki University. His research interests include web geographic information system for local governments, disaster management system, safety confirmation system, regional disaster prevention planning, virtual reality and tele-immersion. $\mathrm{He}$ is a member of IEEE, Virtual Reality Society of Japan (VRSJ) and Visualization Society of Japan (VSJ). 
Tatsuhiro Yonekura received his BS and MS degrees from the Nagoya University in 1979 and 1981, respectively. After working in the Industry System division of Honeywell Co., Ltd in the USA, he received his PhD in Information Science from the Nagoya University in 1991 and joined the Ibaraki University where he is currently a Professor and the Vice President. His current interests include social media and web services.

This paper is a revised and expanded version of a paper entitled 'A study on the operation of infrastructure management system with citizens' participation using the ICT technology' presented at 12th International Workshop on Network-based Virtual Reality and Tele-existence (INVITE'2017), Toronto, Canada, 24-26 August 2017.

\section{Introduction}

In Japan, the aging of social infrastructures which were built during the period of high-speed growth has advanced all at once and the risk of serious accidents and fatal damage is increasing. However, technical experts responsible for taking care of aging social infrastructure are decreasing due to the streamline of administrative structure and the retirement of skilled technicians (Ministry of Land, 2014a).

In addition, due to the revision of the Road Law, road administrators are obligated to periodically conduct inspections and diagnoses on a large number of infrastructures such as tunnels and bridges based on the standard set by the government. The decline of specialised technicians responsible for aging social infrastructure is one of the important topics for maintaining and managing the infrastructure.

It will be difficult to regularly inspect the infrastructure in a traditional way and to implement maintenance and repair because the shortage of human resources and fiscal revenue in the future.

Meanwhile, the public has become aware of the aging of social infrastructure. In the 'national awareness survey' conducted by the Ministry of Land, infrastructure and transportation, half of respondents agree with the opinion of "expansion of resident cooperation in maintenance and renewal of social infrastructure." It is shown that the intention of residents themselves to participate in the maintenance and management as dominant role, such as "cooperation for inspection and reporting of social infrastructure by residents," is becoming stronger (Ministry of Land, 2014b).

In maintaining and managing social infrastructure in the future, it is necessary to impose a certain role on citizens who are also users of social infrastructure and citizen's awareness raising and participation in social infrastructure maintenance and management is one of important measures which should be taken into consideration.

Therefore, collecting fault information of social infrastructure widely through the cooperation with the citizens using the information retrieval tool will contribute to the improvement of the information gathering ability of the administrative office. It can be an effective means for efficiently collecting missing information for the purpose of the formulation for the maintenance management plan of social infrastructure. It is also considered that utilising a system that collects information on faults of social infrastructure from daily life is useful for gathering disaster information and providing information to citizens even in extraordinary situations at large-scale disasters.

However, efforts to maintain and manage infrastructures through citizens partnerships utilising such information gathering tools has not widely spread at present (Kuroki et al., 2015). To popularise this method, it is necessary to improve the satisfaction of both the citizen and the administrative and also to make an effective system and operations that contribute to maintenance and management of infrastructure.

The rest of the article is organised in the followings way. The related work is descried in Section 2. The purpose of our research is descried in Section 3. System configuration of our proposed information collecting tool using mobile terminals systems are explained in Section 4. The information collecting tool using mobile terminals system is described in Section 5. Section 6 evaluates the information collecting tool using mobile terminals system and, finally we conclude our findings and future work in Section 7.

\section{Related work}

Ohno's et al. (2011) research reviewed the area of social infrastructure management in which the administration is responsible for management and focused on creating a mechanism for diversified entities to be responsible for road facility management in collaboration and considering the way people manage regional collaborative road facilities.

However, the research only reached with the suggestion of frameworks and problems of applying it to the actual maintenance remained.

In Yamane et al. (2015), a system combines the position information function and voice function of smart phones in cooperation with the road facility database is implemented by Yamane to provide the state of the road facility in real time during the road patrol, make people to pay attention to the situation and strength the awareness of patrol. However, this system can only be used by road administrators. How to manage the information collected from citizens and utilise it in the maintenance work of social infrastructure was not considered.

In Yoshida (2014), Yoshida considered the possibility of Open311's approach in Japan, which enabled posting on the internet. As a public-private partnership effort, 311 is a 
report number which can be used by citizens to report to the administration under the non-emergency situation.

Specifically, the verification through 'Chiba-repo' which is being held in Chiba City and the verification experiment result in Osaka showed a high possibility of public-private partnership.

'Chiba-repo' is a construction, it means that citizens can report regional issues such as fault information on roads and park equipment to the administration using ICT technology, issues can be shared between citizens and the administration, eventually to make it more efficient and properly to solve those problems.

However, the research did not clarify how to evaluate the behaviour of administrators and how to realise the full-scale introduction of the system into the administration.

Honda (2016) analysed the penetration process of the 'Chiba-repo' application provided by the administration of Chiba from 2014 as a solution platform for regional issues, using the data of registered users of 'Chiba-repo'. The effectiveness of applications for social infrastructure maintenance is not verified.

Furthermore, focusing collective intelligence, Yamagiwa et al. (2011) proposed a system that realises a new ecology-oriented lifestyle that emphasises of life comfort by using 'life log'. Moreover, Peleteiro et al. (2012) modelling a dynamic carpool system that optimises transportation utilisation by ride sharing to improve citizens mobility. On the other hand, we aim to implement a system to manage social infrastructure by contributing citizen's voluntary infrastructure information in this research.

\section{Purpose of this research}

This research aimed to develop an information gathering tools for reporting social infrastructure malfunction, then clarify the intention of introducing this system and present current problems by questionnaire, prove the effectiveness of this system and verify the issues for dissemination.

Up to now, a process of the maintenance of general social infrastructure is, firstly 'check' the targeted social infrastructure by daily inspection and periodic inspections, then 'judge' the state of social infrastructure from the inspection result, after that, take "measures" based on the results. This process is the present maintenance cycle of infrastructures (Figure 1).

All of those works is supposed to be carried out by experts such as administrative, consultants and construction companies.

In the near future, considering the social situation such as the decrease of administrative staffs, the reduction of human resources responsible for maintenance due to mass retirement of experts and technicians, the society cannot only depend on experts, but also need to count on ordinary citizens to do some work they can do. It is necessary to establish a 'social infrastructure management system of citizen cooperation type' to make it work with cooperation between citizen and the administration (Figure 2).
In order to build this social infrastructure management system of citizen cooperation type.

This research aimed to construct A 'citizens' participation with ICT technology' to make it possible and easier for citizens to report the malfunction of social infrastructure, including the situation, the position and the details to the administration in the government.

We are going to clarify the effectiveness of this system and problems to be disseminated by implementing social experiments utilising this system.

Figure 1 Present maintenance cycle of infrastructures

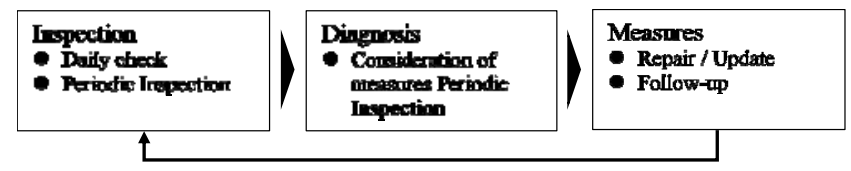

Figure 2 Our proposal maintenance cycle of infrastructures

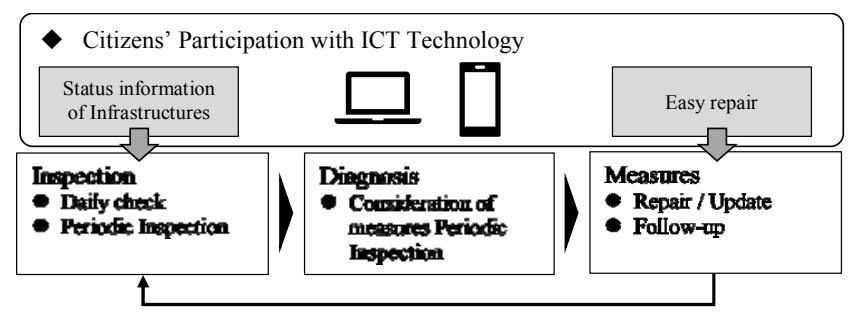

\section{System configuration}

Figure 3 shows the system configuration. The system is constituted by infrastructure information collecting agent, infrastructure administrator agent, infrastructure information application server and database server. Various information registered using this platform is stored in the database server via the infrastructure information application server.

\subsection{Infrastructure information collecting agent}

Utilising the camera function and GPS function of the smartphone, users can post information about malfunctions of social infrastructure. Posted information can be provided to the mobile agent from infrastructure information application server.

\subsection{Infrastructure administrator agent}

The infrastructure administrator agent manipulates the information stored on the database server through the web page. Reporting, editing and deleting functions are provided to the data management agent. The phase of each data (confirmed, in-service and corresponded) is managed here.

\subsection{Infrastructure information application server}

The infrastructure information application server searches the database server and returns searching results according to mobile agent's request. This server also manipulates the data in the database server according to the infrastructure administrator agent. 


\subsection{Database server}

The infrastructure information collected in this research is stored in the database server.

Figure 3 System configuration (see online version for colours)

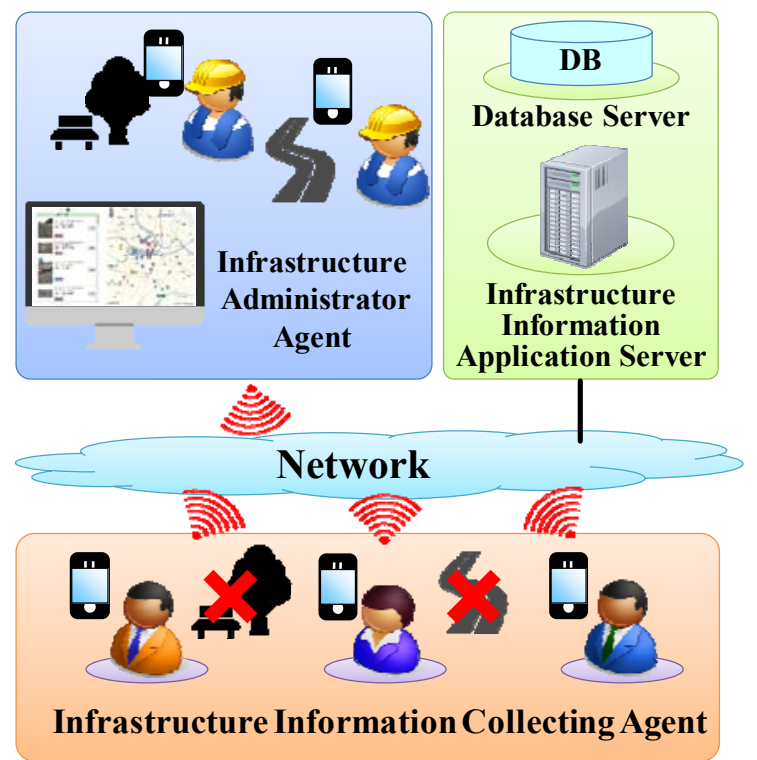

\section{Information collecting tool using mobile terminals}

We assumed that smartphone is the mainly way to collect issues such as infrastructure malfunction information from citizens, focused on three kind of information (position, situation photographs, classification of posted objects) which can be easily posted, made a WEB application which can share information between citizens and government.

The design of the user interface ensures that anyone can use the application with simple operations, even the aged who uses smartphones for the first time in this experiment can use it and post information after a simple training.

The countermeasures shown in Table 1 were implemented in the system against the problems that concerned when the system was introduced to administrative maintenance managers in the past.

\subsection{Data posting system}

The design of user interface enables reporting with minimum action so that any user of the application can post fault information of social infrastructure. The main screen for posting is shown in Figure 4. The pins on the MAP indicate the positions of the information posted so far and the colour of the pins represents the phase of each information. The phase can be managed in three stages including 'information confirmed (red)', 'in progress (yellow)', 'done (light blue)'. As will be described later, only the administrator can change the phase.

Posting behaviour of information starts from 'post' button in Figure 4 and the page will jump to Figure 5. In Figure 5, position information is acquired from the GPS of mobile terminals and a pin will be automatically added to the MAP where the position is.

Table 1 Issues and corresponding

\begin{tabular}{|c|c|c|c|}
\hline No & Issues & Summary & Countermeasure \\
\hline 1 & $\begin{array}{l}\text { Inappropriate } \\
\text { information }\end{array}$ & $\begin{array}{l}\text { The way to deal } \\
\text { with information } \\
\text { that is not related } \\
\text { to infrastructure } \\
\text { management }\end{array}$ & $\begin{array}{l}\text { In order to get } \\
\text { useful information } \\
\text { for the } \\
\text { administration, } \\
\text { classification of the } \\
\text { information to be } \\
\text { posted was preset }\end{array}$ \\
\hline 2 & $\begin{array}{l}\text { Increased } \\
\text { labour }\end{array}$ & $\begin{array}{l}\text { Information } \\
\text { transmission } \\
\text { between the } \\
\text { departments. } \\
\text { When the } \\
\text { information of } \\
\text { another } \\
\text { department is } \\
\text { received. }\end{array}$ & $\begin{array}{l}\text { In accordance with } \\
\text { the classification } \\
\text { added to the posted } \\
\text { information, we } \\
\text { implemented a } \\
\text { function to } \\
\text { automatically } \\
\text { classify the } \\
\text { information so that } \\
\text { only the department } \\
\text { in charge can view } \\
\text { it. We also } \\
\text { implemented a } \\
\text { function for } \\
\text { changing the } \\
\text { department when it } \\
\text { is necessary. }\end{array}$ \\
\hline 3 & $\begin{array}{l}\text { Information } \\
\text { disclosure }\end{array}$ & $\begin{array}{l}\text { Handling of } \\
\text { information } \\
\text { including } \\
\text { personal } \\
\text { information }\end{array}$ & $\begin{array}{l}\text { Information posted } \\
\text { was managed by ID } \\
\text { and PW so that only } \\
\text { those users who } \\
\text { participated in } \\
\text { social experiments } \\
\text { can view it. }\end{array}$ \\
\hline
\end{tabular}

Figure 4 Main screen for posting (see online version for colours)

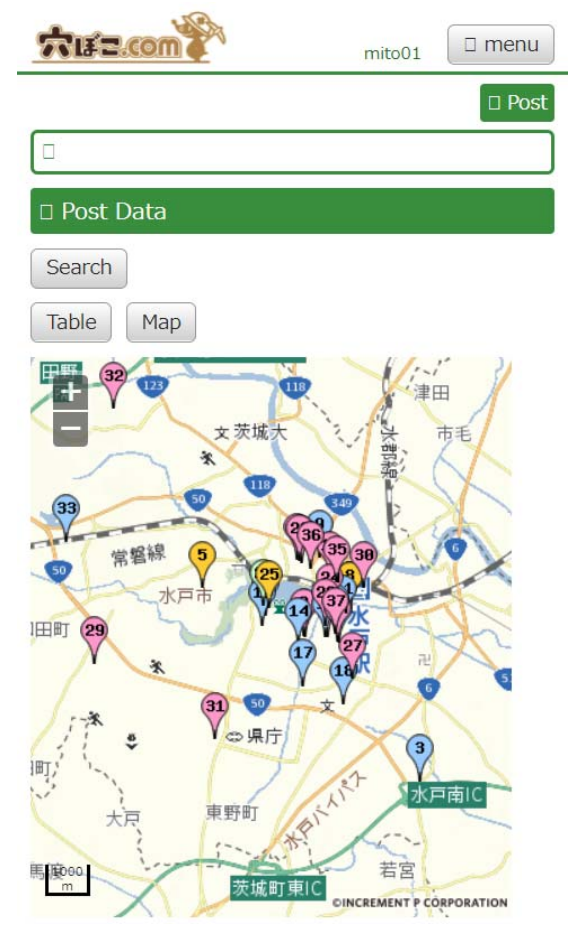


After that, the page can be changed to picture posting screen by click the 'photo' tab. Users can upload up to three photos by activating the camera to taking pictures or selecting photos which are stored in the device (Figure 6).

Figure 5 Position information (see online version for colours)

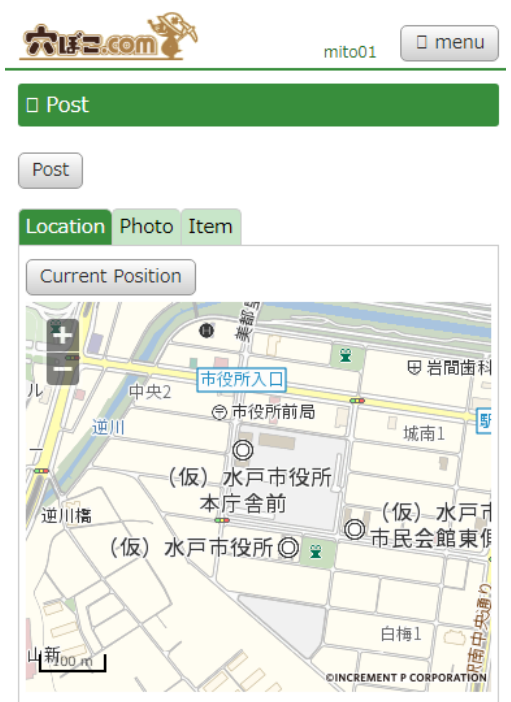

Figure 6 Photographs (see online version for colours)

\begin{tabular}{|c|c|c|}
\hline$\dot{c} 1 x=\operatorname{com}^{2}$ & fukuad & $\square$ menu \\
\hline$\square$ Post & & \\
\hline Post & & \\
\hline Location Photo Item & & \\
\hline 1st photo: & & \\
\hline Choose File No file chosen & & \\
\hline 2nd photo: & & \\
\hline Choose File No file chosen & & \\
\hline 3rd photo: & & \\
\hline Choose File No file chosen & & \\
\hline
\end{tabular}

Figure 7 Classification information (see online version for colours)

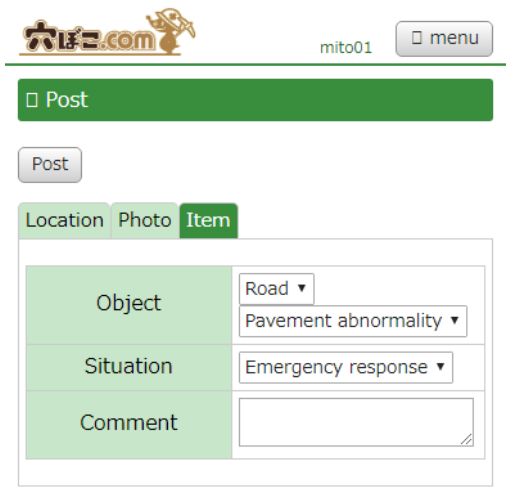

The last 'item' tab is where users post classification information of the posted information (Figure 7). By selecting 'road', 'park', 'water' or 'other' in the option of 'object', a mail will be automatically sent to the department which is supposed to be responsible for the issue.

The sequence diagram of the data posting system is shown in Figure 8.

Figure 8 Sequence diagram of the data posting system

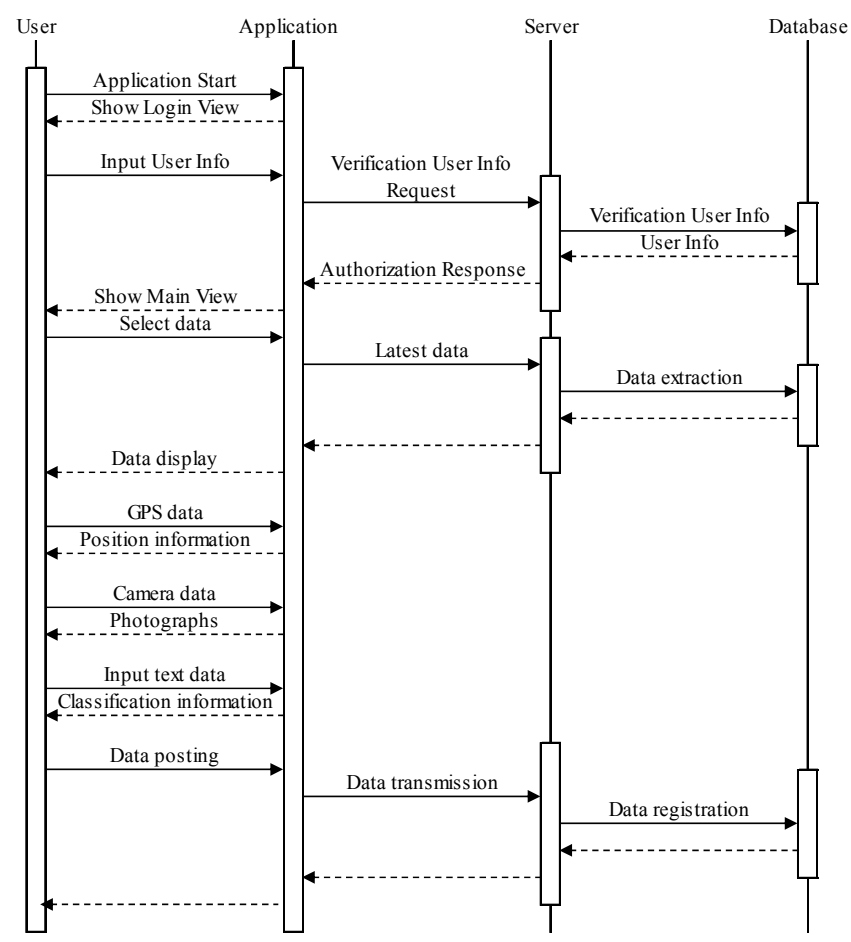

\subsection{Checking a data and to correspond system}

A screenshot of the checking a data and correspond system is shown in Figure 9.

Figure 9 Top screen (see online version for colours)

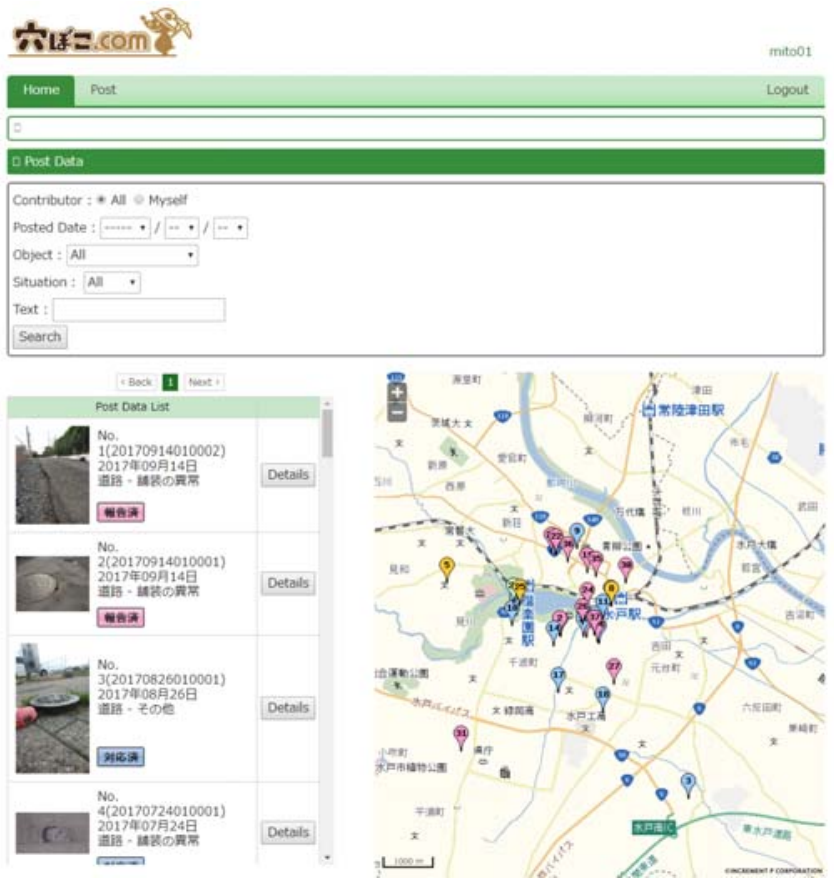


Figure 10 Details data screen (see online version for colours)

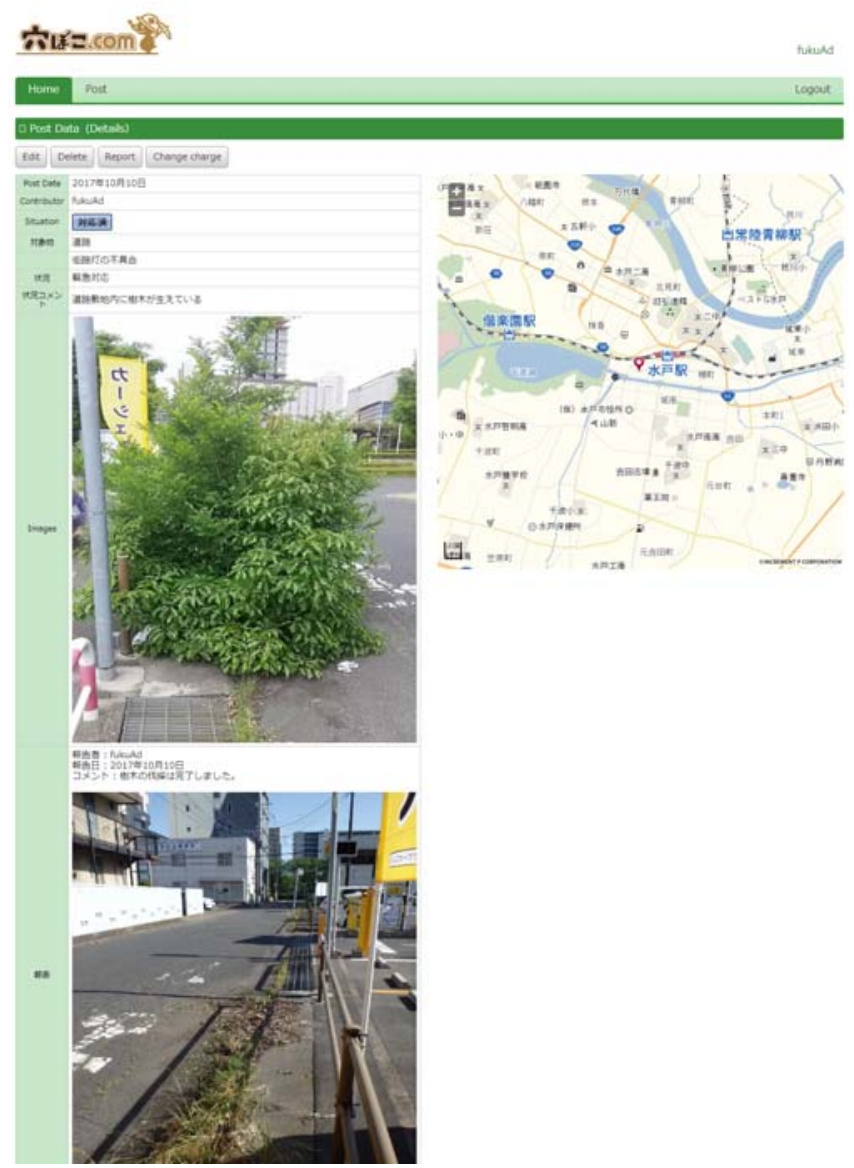

Figure 11 Sequence diagram of the checking a data and correspond system

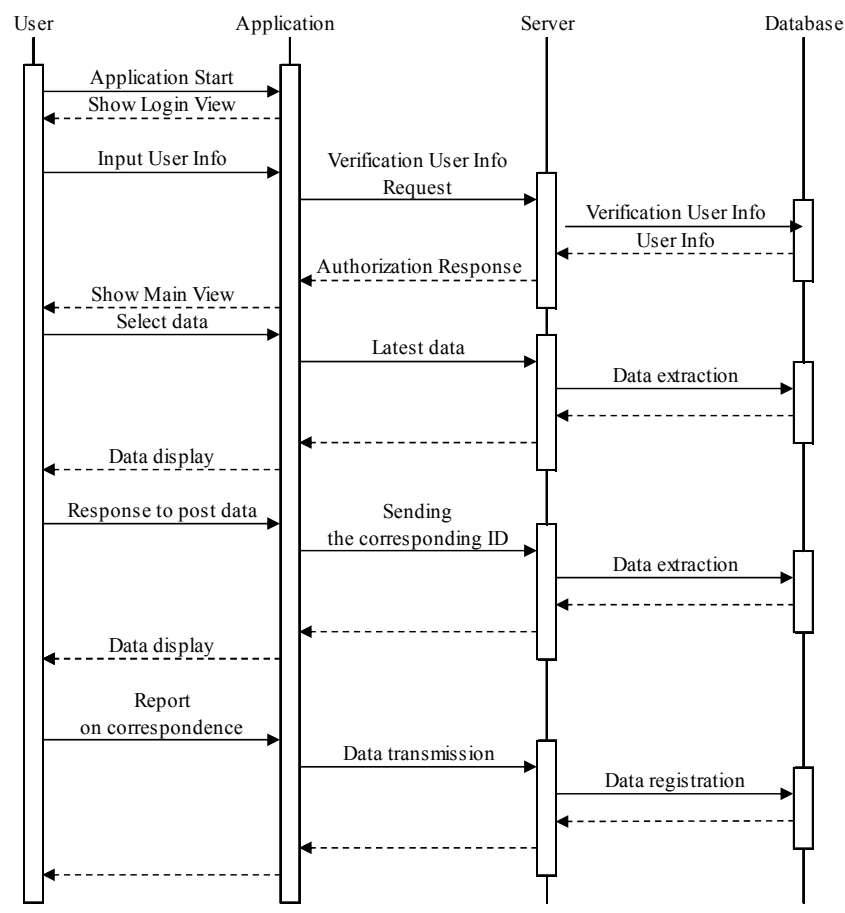

The locations of posted data are marked by pins on the map and the colour of the pins indicates the phase of each post data. By clicking 'detail' or the pin, users can confirm the details of each information.
A screenshot of the confirmation screen for posted details data shown in Figure 10. Authorised administrators can do edition or deletion operations to all the data, but those users who are not authorised (e.g., general citizens) can only edit or delete the data posted by themselves.

For the existing information, it is possible to update the current status by adding photos and comments on the timeline and this information can be fully visible to all the participants.

The sequence diagram of the checking a data and to correspond system is shown in Figure 11.

\section{Social experiment of infrastructure management system with citizens' participation}

\subsection{Outline of social experiment}

Table 2 shows the scale of municipalities where social experiments were conducted. The experiment in A-city and B-city are ongoing from 2017.1.

Table 2 Participating municipalities for social experiment

\begin{tabular}{|c|c|c|c|}
\hline Item & & A-city & $B$-city \\
\hline \multirow[t]{3}{*}{$\begin{array}{l}\text { Municipality } \\
\text { scale } * 2017 / 4\end{array}$} & $\begin{array}{l}\text { Permanent } \\
\text { population }\end{array}$ & 270,528 & 183,637 \\
\hline & $\begin{array}{l}\text { Number of } \\
\text { households }\end{array}$ & 117,989 & 78,542 \\
\hline & Area & $217.3 \mathrm{~km}^{2}$ & $225.6 \mathrm{~km}^{2}$ \\
\hline \multirow[t]{5}{*}{$\begin{array}{l}\text { Social } \\
\text { experiment }\end{array}$} & $\begin{array}{l}\text { Number of } \\
\text { municipal } \\
\text { employees }\end{array}$ & 25 & 4 \\
\hline & $\begin{array}{l}\text { Number of } \\
\text { civic } \\
\text { participants }\end{array}$ & 15 & 15 \\
\hline & \multirow{3}{*}{$\begin{array}{l}\text { Participated } \\
\text { municipal } \\
\text { organisation }\end{array}$} & Road & Road \\
\hline & & Park & --- \\
\hline & & Waterworks & --- \\
\hline
\end{tabular}

Figure 12 Presentation to citizens participating in social experiments (see online version for colours)

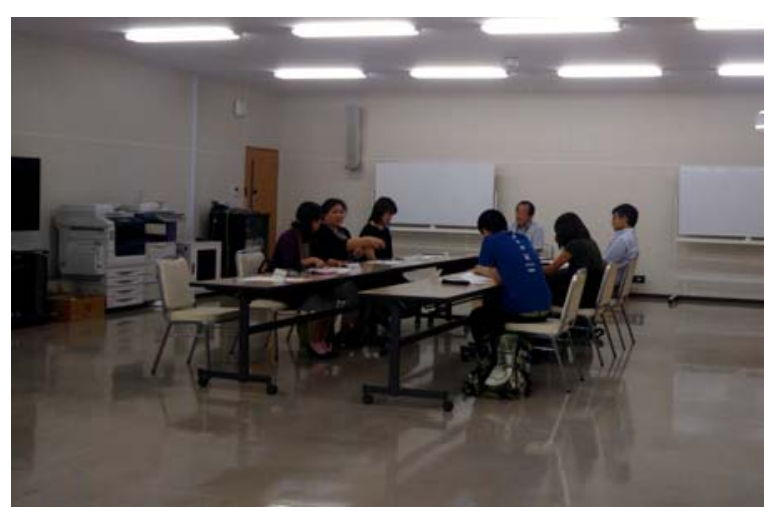

About the outline of the social experiments, three departments (road, park and water) participated in A-city and the administration played a leading role at the beginning. There was only one department participated in 
B-city and the experiment is led by the citizens at the beginning.

A brief session was held before the experiment to explain the objectives of the experiment and the way to use the system (Figure 12).

In this system, posting of information for which personal information is specified in the terms of use is prohibited. In addition, we have set up a privacy policy to use this system. In the unlikely event that information including personal information is posted, the information is deleted at the discretion of administrator agent.

\subsection{Investigation of administrators' awareness about introducing the system}

Before the social experiment, a questionnaire survey about the introduction of civil society collaborating social infrastructure maintenance and management system utilising ICT tools for administrative officials was conducted. The administrators are the object.

In this questionnaire survey for administrative officials, explained what the system is aiming for and the concept of 'open government' beforehand. In addition, this questionnaire survey was conducted not only among the department which is directly related to the maintenance and management of social infrastructure but also gathered representatives from various departments. Results of the questionnaire survey are shown in Figure 13 and Figure 14.

Regarding the introduction of 'open government', since about $70 \%$ of people have expressed positive opinions, it can be said that interest of introduction is high. On the other hand, about the ICT conversion for improving the efficiency of operation processes, the negative opinion is about $60 \%$, which is more than half. Although it is highly expected that citizens participate in politics through ICT, there are many negative opinions on ICT conversion for streamlining operation processes.

Figure 13 Intension of introducing 'open government' (see online version for colours)

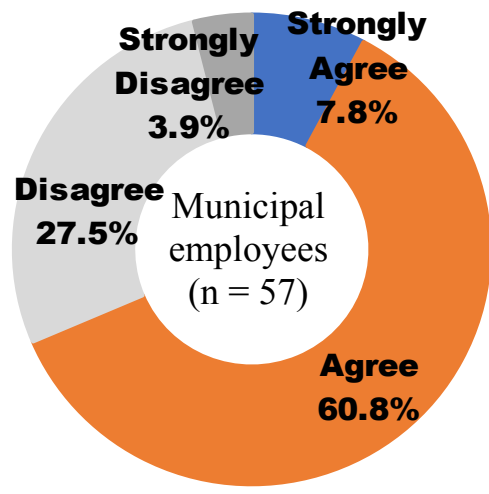

Regarding the ICT introduction, people who supported it think that "because we can know the information visually (by photograph) at the time of receiving contact, we can estimate the amount of human resources and materials." But people who disagree with it think that "since the work has been carried out under the present circumstances, we cannot tell that whether the ICT tool is effective or not." and "the effect of ICT tool varies depending on the competency of the person who are using it."

As for the issues involved with citizens in daily work, they said that "because there are many reports are from the phone call, it is difficult to identify the positions and grasp the contents," "it is difficult for the government to figure out how the citizens think about the information from the government." It can thus be seen that communication with citizens is insufficient and necessary information is lacking.

Figure 14 Introduction of ICT tools leads to efficient business (see online version for colours)

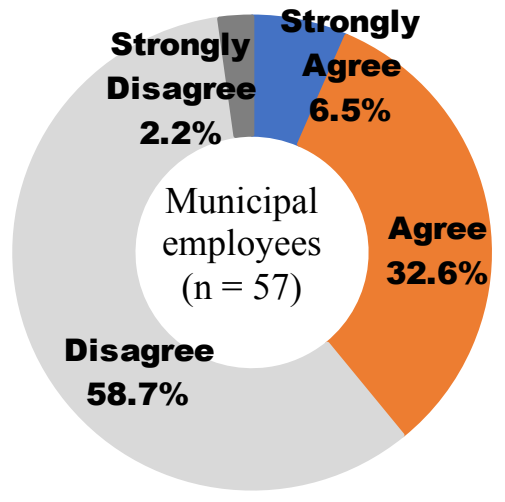

\subsection{Summary of submission data in social experiment}

Table 3 shows the summary of data posted during the social experiment period (ten months between 2017/1-2017/10).

In posted data, 37 are from for A-city and 68 are from B-city. For the breakdown of the submitted data, 57\% was posted by the administration in A-city and $78 \%$ by citizens in B-city. This shows in A-city, the administration led the social whereas in B-city social experiment was led by citizens.

Table 3 Summary result of contribution data

\begin{tabular}{lcc}
\hline Item & A-city & B-city \\
\hline Number of municipal employees & 25 & 4 \\
Number of civic participants & 15 & 15 \\
\hline Implementation period & \multicolumn{2}{c}{$2017 / 1-2017 / 10$} \\
\hline All posted data & $37(100 \%)$ & $68(100 \%)$ \\
$\quad$ form municipal employees & $21(57 \%)$ & $15(22 \%)$ \\
$\quad$ form civic participants & $16(43 \%)$ & $53(78 \%)$ \\
\hline Number of person who posted & 4 & 2 \\
$<$ Municipal employees $>$ & $16.0 \%$ & $50.0 \%$ \\
Number of person who posted & 5 & 12 \\
$<$ Citizen $>$ & $33.3 \%$ & $80.0 \%$ \\
\hline Classification $\quad$ Road & 31 & 65 \\
$\begin{array}{l}\text { information } \\
\text { infed }\end{array} \quad$ Wark & 5 & 1 \\
\hline
\end{tabular}


Among the administrative officials and citizens who participated in the social experiments, the number of administrative staff who actually posted information using the system was $4(16 \%)$ in A-city, $2(50 \%)$ in B-city, the number of citizens was five people $(33 \%)$ in A-city and 12 people $(80 \%)$ in B-city. Table 4 (A - city) and Table 5 (B-city) show the number of individual submissions by administrative officials and citizens who actually posted information. In both cities, there are some certain participants posted a lot. In the future, in order to improve this system, it is particularly necessary to increase such active participants.

Table 4 Summary result of individual contribution data (A-city)

\begin{tabular}{lcc}
\hline Item & Person no. & $\begin{array}{c}\text { The number of post } \\
\text { data }\end{array}$ \\
\hline Number of person who & $\mathrm{A}$ & 11 \\
posted $<$ municipal & $\mathrm{B}$ & 5 \\
employees $>$ total & $\mathrm{C}$ & 4 \\
number of person $=25$ & $\mathrm{D}$ & 1 \\
& Subtotal & 21 \\
Number of person who & $\mathrm{a}$ & 9 \\
posted $<$ citizen $>$ total & $\mathrm{b}$ & 3 \\
number of person $=15$ & $\mathrm{c}$ & 2 \\
& $\mathrm{~d}$ & 1 \\
& $\mathrm{e}$ & 1 \\
& Subtotal & 16 \\
\hline
\end{tabular}

Table 5 Summary result of individual contribution data (B-city)

\begin{tabular}{lcc}
\hline Item & Person no. & $\begin{array}{c}\text { The number of } \\
\text { post data }\end{array}$ \\
\hline Number of person who & $\mathrm{A}$ & 14 \\
posted $<$ municipal & $\mathrm{B}$ & 1 \\
employees $>$ total & Subtotal & 15 \\
number of person $=4$ & $\mathrm{a}$ & 18 \\
Number of person who & $\mathrm{b}$ & 14 \\
posted $<$ citizen $>$ total & $\mathrm{c}$ & 8 \\
number of person $=15$ & $\mathrm{~d}$ & 3 \\
& $\mathrm{e}$ & 2 \\
& $\mathrm{f}$ & 2 \\
& $\mathrm{~g}$ & 1 \\
& $\mathrm{~h}$ & 1 \\
& $\mathrm{i}$ & 1 \\
& $\mathrm{j}$ & 1 \\
& $\mathrm{k}$ & 1 \\
& 1 & 1 \\
& Subtotal & 53 \\
\hline Total & & 68 \\
\hline
\end{tabular}

Representative posting data is shown in Figure 15 to Figure 17.

Figure 15 is a malfunction on the road posted by citizens. The post showed that the handwheel on the sidewalk was protruding from the road and it was dangerous. People may trip over the handwheel and in some cases, the administrators need to take the responsibility of maladministration. The administrative officer has completed the aid measures within one week and added a comment on this system saying that full-scale repair work will be carried out in the future. Administrative officials are trying to find defects in social infrastructure through regular inspections and daily patrols, there is a possibility that issues may be missed and citizens who are users of the road can check the road every day. Therefore, we think that there is a possibility of development for this system.

Figure 15 Malfunction on the road (see online version for colours)

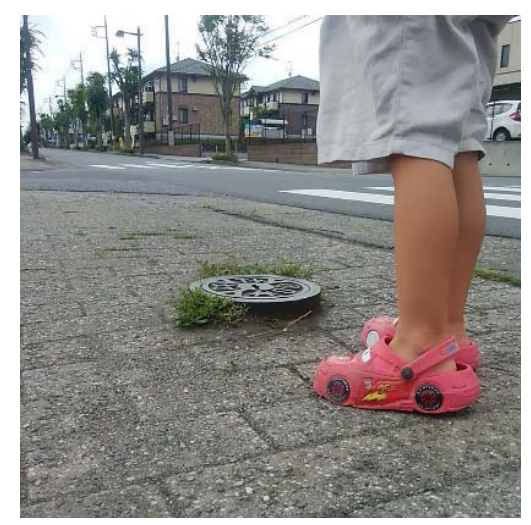

Figure 16 Malfunction on the park (see online version for colours)

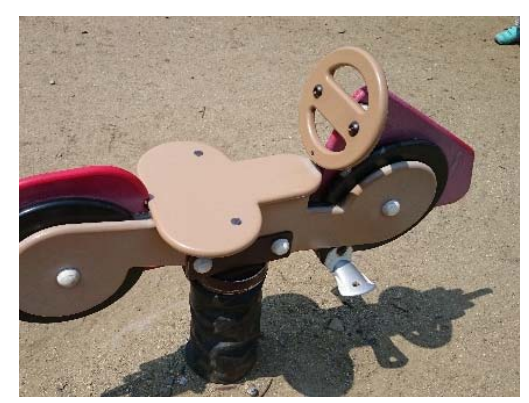

Figure 16 is a malfunction of the park equipment posted by the citizen. A part of the handle bolt was loose and fingers may be pinched. The administrative of the park has fixed it on the second day after the submission. Inspection of park equipment is conducted by experts once a year on a regular basis according to the laws and regulations. By utilising the system, the daily inspection by citizens can be the supplement between periodic inspections to find the little problems which only can be noticed by the actual users.

Figure 17 is a report on the cleaning activities of weeds that flourished along the road. It showed a success maintenance example of the citizen collaboration carried out by the self-governing association, which is exactly the goal of this system. The waste discharged due to the cleaning 
work can be collected in the dedicated garbage bag prepared by the administration and left on the side of the road; the administration will collect the waste later. In addition, the garbage bags are for free. We interviewed the citizens who participated in the social experiments; it seems most residents did not get the information yet. We are planning to introduce it as an 'example of initiatives' in the future by using the system.

Regarding the reliability of information posted from citizens, according to social experiments conducted in 2015 (Kuroki et al., 2015), in about the same social experiments targeting citizens with high collaboration awareness, about $70 \%$ of posted data is useful information It was. In the social experiment of this time as well, participation in 'citizen monitor' with understanding of administrative management and highly awareness of cooperation, the reliability of the posted information is high. On the other hand, when this system is generalised and spread to the whole citizen, it is necessary to consider measures to improve the reliability of information.

Figure 17 Cleaning activities of the road (see online version for colours)

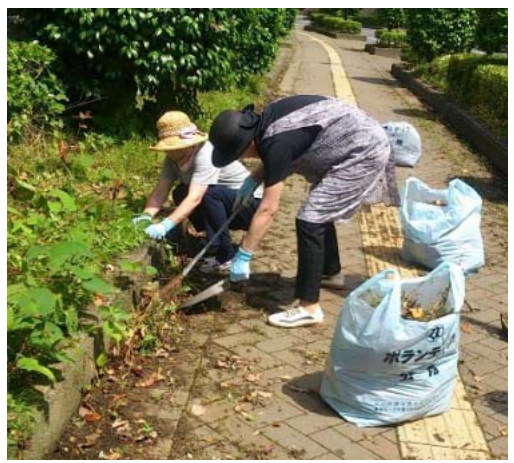

\subsection{Questionnaire survey on citizens and administrative staffs who participated in social experiment}

To clarify the intention of introducing the system and to figure out their expectation on the system, before the social experiment and nine months after that, a questionnaire survey on citizens and administrative staff who participated in this social experiment was conducted twice.

Before the social experiment, none of them thought that 'the system should not be introduced' in both the administrative and the citizen side, $44.4 \%$ of administration and $70.0 \%$ of citizens thought that it should be introduced. (Figure 18).

When asked about the introduction of the system by free description formulas, many administrative officials said, "the problems about how to utilise the system should be considered." And on the citizen side, a high expectation on the system in the case when citizens do not know which department they should contact was shown. "Maybe those problems can be solved by using the system."
Figure 18 Intention to introduce the system (see online version for colours)

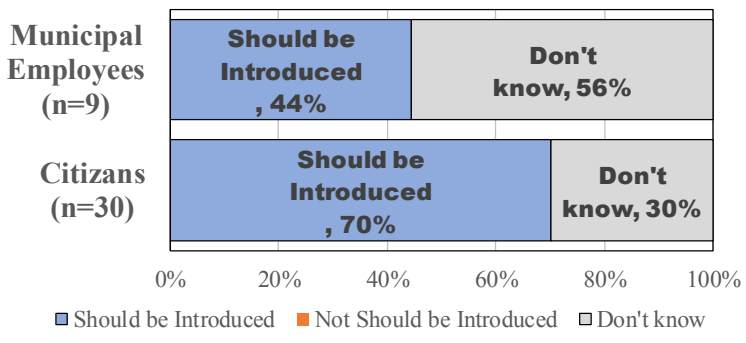

After nine months, we asked the administrators and the citizens about the mechanism, both sides gave a positive evaluation (Figure 19). When asked about the usability of the system, that $38 \%$ of the administrative side and $32 \%$ of the citizen side gave a negative evaluation (Figure 20). We need to focus on the usability in the future.

We calculated average value and standard deviation in the case where 'not at all well' was 0 , 'slightly well' was 1 , 'moderately well' was 2 and 'very well' was 3 . For municipal employees 'about this social experiment' and 'system usability', the average was 2.22, 1.50, standard deviation $0.416,1.011$. Meanwhile, for the citizen's 'about this social experiment' and 'system usability', the average was $2.43,1.70$, standard deviation $0.536,0.866$. The difference between administration and citizen's evaluation is relatively small.

Figure 19 About this social experiment (see online version for colours)

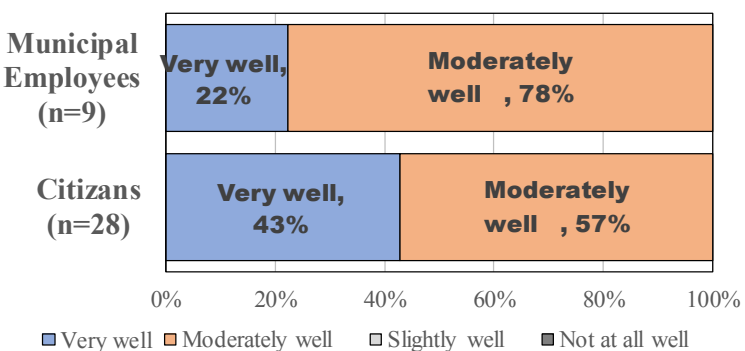

Figure 20 System usability (see online version for colours)

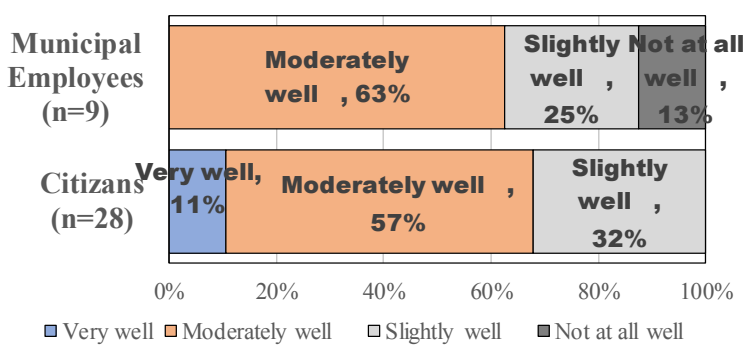

We also made the administrative officials to evaluate the content of posted information from citizens, the result showed that $62.5 \%$ of those information is good (Figure 21). It can be said that there is possibility useful information can be gathered for administrative staff by utilising this system.

Secondly, considering the small amount of posts from citizens, we asked about the frequency the citizens who participated in the social experiment check the HP of this system, $70 \%$ of them answered once a month and $0 \%$ of 
them check it every day (Figure 22). It is very clear that we need to find a solution to make users use the system every day. We also asked the participants who never posted anything to the system why they did not do it. Most of them answered that "I could not find a problem worth a post."

In this social experiment, the number of post was five to six cases every month which is less than the expectation. We considered that low motivation of the citizens was not the reason. It was caused by that the citizens cannot find the fault information.

Finally, both the administrative and citizens thought that this initiative should be continued, so it can be said that the system got a high expectation (Table 6).

Figure 21 Evaluation of data submitted by citizens (see online version for colours)

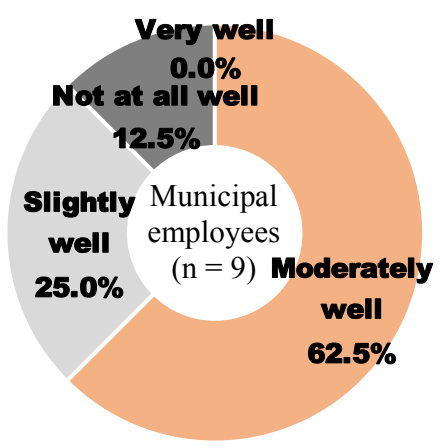

Figure 22 Frequency of accessing the system (see online version for colours)

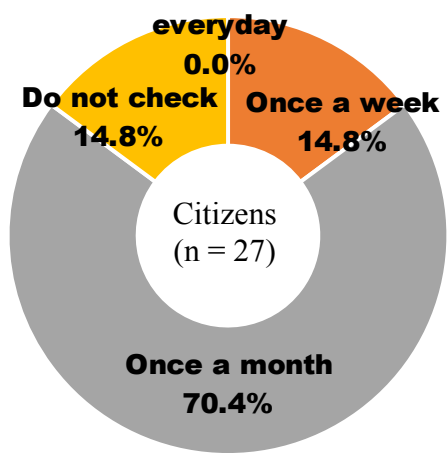

Table 6 Continue intention of this initiative

\begin{tabular}{lcc}
\hline & $\begin{array}{c}\text { Should be } \\
\text { continued }\end{array}$ & $\begin{array}{c}\text { Not necessary to } \\
\text { continue }\end{array}$ \\
\hline Citizens & 27 & 0 \\
Municipal employees & 9 & 0 \\
\hline
\end{tabular}

\section{Conclusions and future works}

In order to build a social infrastructure management system with the collaboration from citizens, a 'citizens' participation with ICT technology' was constructed in this research to make it possible for citizens to report the damage of social infrastructure, including the situation, the position and the details to the administration in the government. Via social experiments utilising this system, we verified the effectiveness of this system and found the problems for dissemination. In the future, in order to spread this system widely, it is necessary to deal with the following issues.

- We assumed that smartphone is the mainly way to collect issues such as infrastructure malfunction information from citizens, focused on three kinds of information (position, situation photographs, classification of posted objects) which can be easily posted, made a WEB application which can share information between citizens and government. Even the elderly, who used the smartphone for the first time in this experiment, can post information using this application after a simple training.

- Although the system got a positive evaluation in usability, there are still $38 \%$ of the administrative side and $32 \%$ of the citizen side thought that it was not very good in the questionnaire survey, it is necessary to improve the usability in the future.

- Questionnaire survey for administrative officials revealed that more than $70 \%$ of them are interested in introduction of opening government. On the other hand, regarding the ICT conversion for improving the efficiency of operation processes, the negative opinion is about $60 \%$, which is more than half.

- Among the administrative officials and citizens who participated in the social experiments, the number of administrative staff who actually posted information using the system was $4(16 \%)$ in A-city, $2(50 \%)$ in B-city. The number of citizens was 5 in A City (33\%) and 12 in B-City (80\%).

- By utilising this system, we found a possibility to collect useful information from citizen's point of view, which cannot be found by regular inspections conducted by the administration or daily patrols.

- Both the administrators side and the citizen side gave a positive evaluation on this initiative

- In this social experiment, the number of post was 5 to 6 cases every month which is less than the expectation. We considered that low motivation of the citizens was not the reason. It was caused by that the citizens cannot find the fault information.

\section{References}

Honda, M. (2016) 'Estimate of the penetration process of the administrative application based on registrant information made open data of "Chiba-repo", Beyond the Information Technology, Vol. 26, No. 2, pp.187-194.

Kuroki, M., Ishida, T. and Yonekura, T. (2015) 'A study on the operation of infrastructure management system with citizen participation utilizing the ICT technology', Papers of Research Meeting on Civil Engineering Planning, June. 
Ministry of Land (2014a) Land, Infrastructure, Transport and Tourism in Japan, White paper on Infrastructure and Transport, pp.28-92.

Ministry of Land (2014b) Land, A Basic Plan for Extending Service Life of Infrastructure (Plan of Actions), 2014-2020, White Paper on Infrastructure and Transport, p.16.

Ohno, S., Takagi, A. and Demura, Y. (2011) 'A study on governance and human resources for cooperative road facilities management', Journal of JSCE (F4), Vol. 67, No. 4, pp.I_145-I_158.

Peleteiro, A., Burguillo, J.C., Armendáriz, M., Arnould, G. and Khadraouim, D. (2012) 'Modelling and simulating a dynamic carpooling system for improving citizens mobility', International Journal of Space-Based and Situated Computing, Vol. 2, No. 4, pp.209-221.
Yamagiwa, M, Murakami M and Uehara M. (2011) 'Sensing, collecting and discovering the home environment information for ecological lifestyle', International Journal of Space-Based and Situated Computing, Vol. 1, Nos. 2/3, pp.113-121.

Yamane, S., Yasumura N. and Yoshitake, T. (2015) 'Development and practical use of road infrastructure deterioration voice guidance system using high-performance mobile phone as a real-time forecasting system', Journal of JSCE (F3), Vol. 71, No. 1, pp.12-29.

Yoshida, H. (2014) 'New opportunities for Japanese open government by Open311', Proc. of the Annual Conference of Japan Society for Management Information 2014 Autumn, October, pp.49-52. 